\title{
The role of eye camps in rural areas of Nepal
}

\author{
Gurung $\mathbf{J}^{1^{*}}$, Tuladhar $\mathbf{S}^{2}$, Sharma $\mathbf{A}^{3}$ \\ 'Lecturer, ${ }^{2}$ Associate Professor, Department of Ophthalmology, Gandaki Medical College \& \\ Teaching Hospital, Pokhara, Nepal \\ ${ }^{3}$ Ophthalmologist, Kirtipur Eye Hospital, Kathmandu, Nepal
}

\section{Keywords}

Eye camp, Blindness, Cataract surgery

\section{*Corresponding author}

Dr. Jamuna Gurung

Lecturer, Department of Ophthalmology

Gandaki Medical College \& Teaching Hospital,

Pokhara, Nepal

Email: jamunaorama@gmail.com

\section{ABSTRACT}

Objective: To evaluate the role of eye camp in reducing avoidable blindness in Nepal.

Methods: A cross sectional camp-based study was conducted in a remote village of Eastern Nepal, where a six days eye screening and free surgical camp was done.

Results: A total of 467 people were screened, where 280 (60\%) were males and 187 (40\%) females. Mean age of the patient was 47.6 years. Age related cataract $165(17.7 \%)$ was the commonest cause of decreased vision followed by refractive error 105 (11.2\%). Among 165 cataract patients, 81 (49.1\%) underwent cataract surgery. The mean age of the operated patient was 74.9 years. Among the operated eyes, visual impairment was present in 56 (69.1\%) eyes and blindness in 25 (30.9\%). After cataract surgery, visual acuity was restored to 6/6-6/18 in 58 (71.6\%), 6/24-6/60 in 18 (22.2\%) and five (6.2\%) had visual acuity of $<6 / 60$. The causes of poor visual acuity in these patients were corneal edema (three cases), anterior uveitis (1 case) and optic atrophy (1 case). Pterygium excision (seven cases), entropion correction (two cases), chalazion I\&C (one case) were other surgery performed in the camp. Refractive error was corrected by prescribing glasses.

Conclusion: Cataract was found to be the major cause of blindness followed by refractive error. Conducting eye screening and surgical camps helps in restoring vision to the residents of remote areas, thus reducing the burden of blindness due to cataract and refractive error.

\section{INTRODUCTION}

Eye camps are an important way of delivering quality eye health care. The surgery in eye camps is marginally economical and more accessible. The people in Nepal are still deprived of proper eye health care due to the challenging geography of the nation, illiteracy and poor socio-economic status. Conducting surgical eye camps provide effective and accessible eye care which helps in reducing the burden of eye disease.

Globally, 285 million people are visually impaired, out of which 39 million are blind. The major causes of visual impairment are uncorrected refractive errors (43\%) followed by cataract (33\%) and about $90 \%$ of the world's visually impaired live in developing countries. ${ }^{1,2} \mathrm{Nepal}$ National Blindness Survey in 1981 showed the prevalence of blindness has declined from $0.84 \%$ in 1981 to $0.39 \%$ in 2010.,4 The major cause of blindness was cataract (72\%) in 1981 which has declined to $65 \%$ of blindness in 2010.,4 The burden of reversible blindness due to cataract for the underprivileged people remains a great concern for the country. Therefore, conducting surgical eye camps in the remote and mountainous areas will help in the prevention and control of blindness in Nepal. 
The present study was done to assess the role of eye camp in reducing the avoidable blindness in Nepal. This was a six days surgical eye camp in the remote village of Tehrathum district of Eastern Nepal which was conducted by Biratnagar Eye Hospital. This hospital organizes such camps every year covering Eastern region of Nepal.

\section{MATERIALS AND METHODS}

This was a cross sectional camp-based study done for six days in an Eastern region of Nepal where free eye screening and surgery was provided. The team included one ophthalmologist, two ophthalmic assistants, one ophthalmic technician, nurses and paramedics.

Eye screening was conducted in an eye care center present in Tehrathum district and those patients with ocular problems were analyzed. Refraction was performed in all the patients with decreased visual acuity and glasses were prescribed as needed. Treatment of minor ocular conditions was done at the examination site. Those who required cataract surgery were further evaluated. Informed written consent was taken from the patients. The health post building was sterilized a day before the surgery. Manual small incision cataract surgery was performed with fish hook technique. Under aseptic precautions, the eye to be operated was draped after peribulbar anesthesia. Conjunctival peritomy was done. Frown shaped partial thickness scleral tunnel was made followed by AC entry 1 to $2 \mathrm{~mm}$ into the clear cornea with keratome knife. Viscoelastic substance was injected into the anterior chamber and capsulotomy was done with cystitome. Nucleus delivery was done with fish hook technique. After irrigation and aspiration of the cortical matter, PMMA IOL was inserted into the capsular bag. Viscoelastic was removed from anterior chamber with a simcoe and intracameral cefuroxime $(0.1 \mathrm{~mL}$ of $10.0 \mathrm{mg} /$ $\mathrm{mL}$ ) was injected after formation of anterior chamber. Sub conjunctival injection of dexamethasone $(2 \mathrm{mg})$ and gentamicin (20 mg) was given at the end of the procedure.

The patients were discharged on topical medication comprising of combination of ofloxacin and dexamethasone six times daily and tapered over six weeks. A follow-up was conducted at the same eye care center four to six weeks after surgery. Data obtained were entered in Microsoft Excel 2010 and analysed using SPSS 22.0 version.

\section{RESULTS}

A total of 467 people were examined during the eye screening program. The mean age was 47.6 years. The age range of the patients is shown in Table 1.There was a female preponderance $(60 \%)$ compared to male (40\%) with female to male ratio of 1.5:1. (Figure 1)

\begin{tabular}{cc}
\hline Age Group & No of patients $\mathbf{n}(\%)$ \\
$0-20$ & $72(15.4)$ \\
$21-40$ & $95(20.3)$ \\
$41-60$ & $159(34)$ \\
$>60$ & $141(30.2)$ \\
Total & 467 \\
\hline
\end{tabular}

Table 1. Age group of the patients

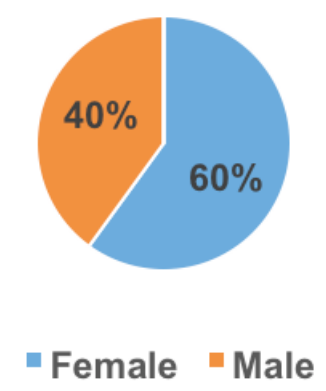

Figure 1. Gender distribution of the patients

They presented with different ocular problems which are listed in Figure 2. Age related cataract (17.7\%) was the commonest cause of decreased vision followed by refractive error (11.2\%).

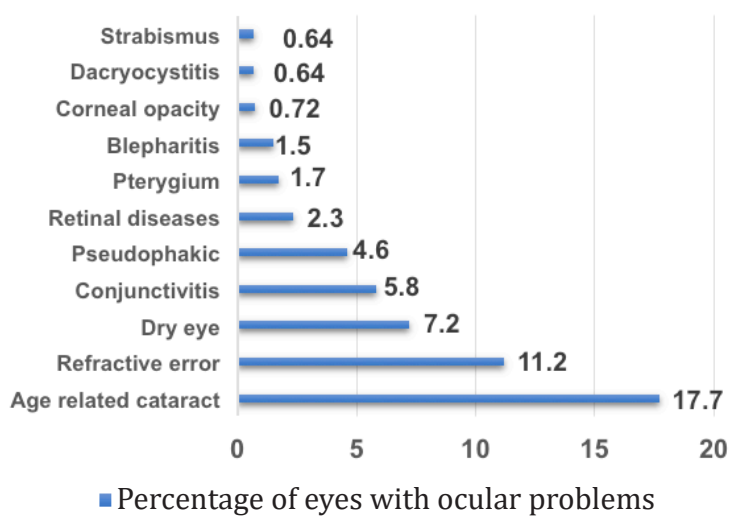

Figure 2. Common eye diseases among camp patients

Out of 165 eyes with cataract, 80 underwent small incision cataract surgery with PCIOL implantation and one patient had intracapsular cataract extraction with ACIOL implantation. The mean age of the operated patient was 74.9 years. Among the operated patients, 53\% were 
females and $47 \%$ were males. Bilateral cataract surgery was performed in two patients. The presenting visual acuity was recorded using the WHO categories of visual impairment (Figure 3). Visual impairment was present in 56 (69.1\%) eyes and blindness in 25 (30.9\%).

At the time of discharge, 76 of 81 operated eyes (94\%) had visual acuity of $6 / 60$ or better and $5(6 \%)$ had less than $6 / 60$ (Figure 3). Cause of low vision in these cases was corneal edema ( 3 cases), anterior uveitis ( 1 case) and optic atrophy(1 case). There were two cases of posterior capsular rent, 1 requiring ACIOL and IOL was placed in the sulcus in other case.

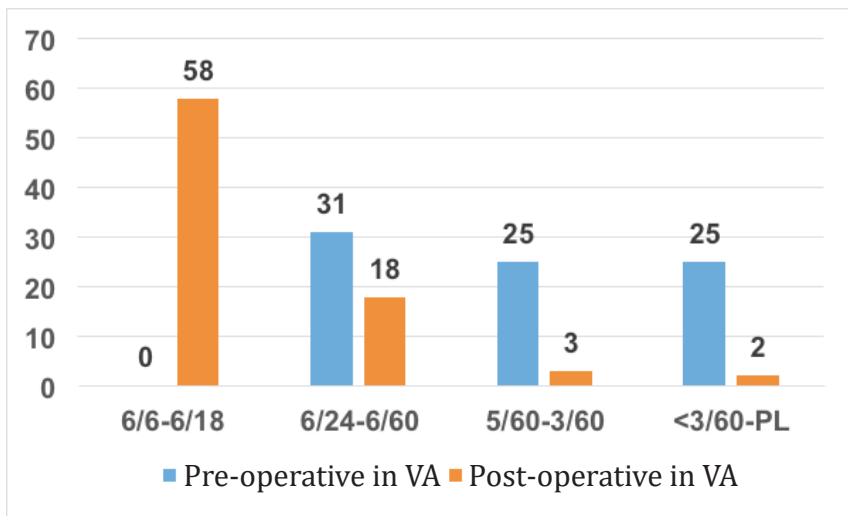

Figure 3. Pre and Post-operative visual acuity (n)

Pterygium excision (7 cases), entropion correction (2 cases), chalazion I \& C (1 case) were other surgery performed in the camp. (Figure 4)

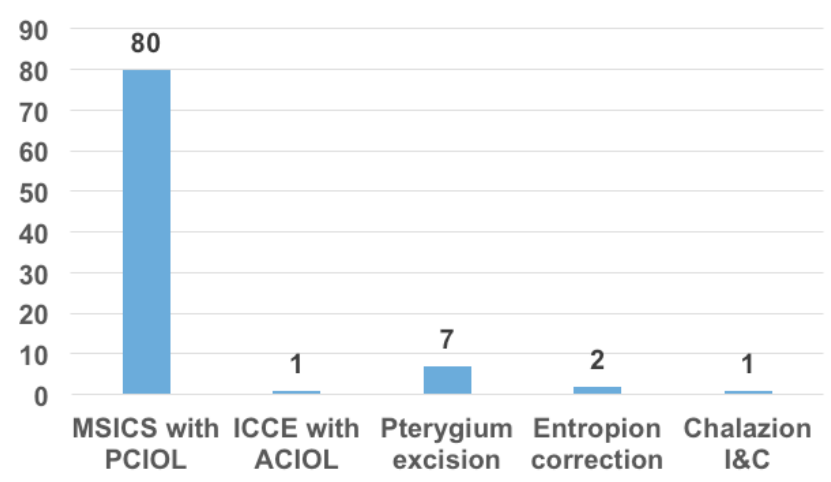

Figure 4. Types of surgery performed

\section{DISCUSSION}

Cataract is the leading cause of blindness in Nepal. The prevalence of blindness is high in remote areas due to different barriers like lack of facility, geographical distribution, unaware of treatment and low economic status. ${ }^{4}$ Therefore, surgical eye camps have an important role to decrease the burden of cataract related blindness.

In our study, there was increased number of females (53\%) than males (43\%) which is comparable to the study by Sitoula et $\mathrm{al}^{5}$ and Pradhan et al. ${ }^{6}$ This could be due to the fact that they are deprived of health care facility and are dependent both economically as well as physically on their family members. Hence they become the target group to benefit the most from such camps. Moreover, the prevalence of blindness is more in females than males. ${ }^{4}$ The average age of the patient was 74.9 years which was similar to the study by Sitoula et al. ${ }^{7}$

Small incision cataract surgery with PCIOL implantation was the choice of surgery in our study. Previously, ICCE was the standard surgical technique which had more complications and patient needed an aphakic glasses. However, there is increasing trend in SICS because it is cheaper, has easy learning curve with fewer complication and is suitable for high volume cataract surgery especially in developing nation. ${ }^{8}$

In patients undergoing cataract surgery, visual impairment was present in 56 (69.1\%) eyes and blindness in 25 (30.9\%). At the time of discharge, $76(93.8 \%)$ attained VA $6 / 60$ or better and 2 were blind $(<3 / 60)$. In other study by Sitaula et al, 40 eyes were blind and visual impairment in 20 eyes which improved to $6 / 60$ or better in $54(90 \%)$ eyes after surgery which is comparable to our study. Complications like posterior capsular rent, corneal edema, anterior uveitis and pre-existing optic atrophy were noted. Such complications were also noted in other study. ${ }^{5,7}$

In our analysis, refractive error was found in $11.2 \%$ cases. The study by Nepal et $\mathrm{al}^{9}$ and Shrestha et $\mathrm{al}^{10}$ reported the prevalence of refractive error among school children to be 8.1 and $11.9 \%$ respectively.

\section{CONCLUSION}

Cataract seems to be a major cause of blindness in Nepal. There should be expansion of infrastructure, human resources with financial sustainability to provide eye care facility in remote rural areas. Similar eye camps should be conducted regularly to provide service to the underprivileged people. Surgical eye camps covering people of remote areas have an important role to combat the burden of this preventable cause of blindness. 


\section{ACKNOWLEDGEMENT}

Our immense thanks to Prof. Dr. Sanjay Kumar Singh for this opportunity and Mr. Shikendra Thakur, Mr. Dev Shah, health assistants and other staffs for their support. We are grateful to Biratnagar Eye Hospital for providing service to people of remote areas by organizing free surgical eye camps every year.

\section{REFERENCES}

1. Pascolini D, Mariotti SP. Global estimates of visual impairment: 2010. Br. J Ophthalmol. 2012;96(5):614-8.

2. Mid Term Review of Vision 2020: The Right to Sight. Apex Body for Eye Health. Nepal: Ministry of Health and Population 2011.

3. Brilliant GE, Pokhrel RP, Grasset NC. The epidemiology of blindness in Nepal: Report of the 1981 Nepal Blindness Survey. Chelsea, USA: The Seva Foundation, 1988.

4. Sapkota YD. The Epidemiology of Blindness in Nepal: 2012. Kathmandu: Nepal Netra Jyoti Sangh; 2012.

5. Sitoula RP, Sarkar I, Nayak D, Singh SK. Lens induced glaucoma: An experience in tertiary eye care center in eastern Nepal. Nepal J Ophthalmol. 2016;8(16):161-6.

6. Pradhan D, Hennig A, Kumar J, Foster A. A prospective study of 413 cases of lens-induced glaucoma in Nepal. Indian J Ophthalmol. 2001;49:103-7.

7. Sitaula RK, Joshi S, Khana Sl. Surgical Eye Camp In Rural Area Of Nepal And Its Role In Vision 2020.Journal of Chitwan Medical College 2016;6(16):1-5.

8. Kapoor H, Chatterjee A, Daniel R, Foster A. Evaluation of visual outcome of cataract surgery in an Indian eye camp. Br J Ophthalmol.1999;83:343-6.

9. Nepal BP, Koirala S, Adhikari S, Sharma AK. Ocular morbidity in school children in Kathmandu. Br J Ophthalmol. 2003;87(5):531-4.

10. Shrestha RK, Joshi MR, Ghising R, Rizyal A. Ocular morbidity among children attending Government and private schools of Kathmandu Valley. J Nepal Med Assoc. 2011;51(184):182-8. 